\title{
Percepçáo de estudantes de Terapia Ocupacional frente ao atendimento de pacientes com hanseníase ${ }^{1}$
}

\author{
Rogério Dubosselard Zimmermann ${ }^{a}$, Sémares Genuino Vieira ${ }^{b}$, Nara Carollina Mattos Sandes ${ }^{b}$, \\ Thaisa Damasceno de Albuquerque Angelo ${ }^{b}$, Viviane Cássia Aranda de Souza ${ }^{b}$
}

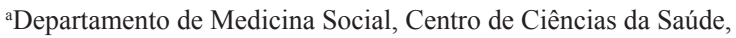
Universidade Federal de Pernambuco - UFPE, Recife, PE, Brasil

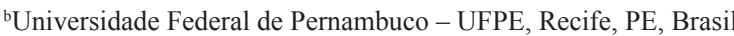

\begin{abstract}
Resumo: Introdução: O Brasil é considerado o segundo país mais endêmico para hanseníase no mundo. Apesar do crescente investimento em prevenção e informação da população, o estigma que envolve a morbidade dificulta seu diagnóstico e tratamento. Com uma abordagem biopsicossocial, o terapeuta ocupacional compõe a equipe multiprofissional que presta assistência ao hanseniano. Objetivo: Conhecer a percepção dos profissionais em formação acadêmica frente ao atendimento de pacientes acometidos de hanseníase. Metodologia: Foi realizada uma pesquisa qualitativa de caráter descritivo exploratório, com alunos do curso de graduação em Terapia Ocupacional de uma universidade pública. Utilizou-se como técnica de coleta de dados uma entrevista aberta semiestruturada, que abordou a expectativa dos estudantes com relação ao primeiro contato com o paciente hansênico, como se sentiram nesse momento, a influência do comportamento da turma, como foi o preparo para realizar o atendimento e o interesse em continuar atuando na área. Resultados: Observou-se que os estudantes possuem conhecimento sobre a doença, o agente causador, a forma de transmissão, suas implicações físicas e sociais, e que o acesso à informação foi de extrema importância para que a maioria dos alunos não criasse expectativas negativas em relação ao atendimento desses pacientes. Conclusão: O estudo demonstrou como a hanseníase ainda provoca medo na população e que esse fato pode influenciar o comportamento do profissional de saúde caso ele não tenha capacitação para lidar com o paciente.
\end{abstract}

Palavras-chave: Hanseníase, Estigma Social, Terapia Ocupacional.

\section{Perception of Occupational Therapy students towards the care of patients with leprosy}

\begin{abstract}
Introduction: Brazil is considered the second most endemic country in the world for Hansen's disease. Despite the growing investment in prevention and public information, the stigma surrounding morbidity hinders its diagnosis and treatment. With a biopsychosocial approach, the occupational therapist composes the multidisciplinary team providing care for lepers. Objective: Therefore, it is important to know the perceptions of professionals under academic training towards the care of patients suffering from leprosy. Methods: It is a qualitative exploratory-descriptive research carried out with undergraduate students of Occupational Therapy from a public university. An open semi-structured interview was used as technique for data collection; it addressed students' expectation about the first contact with leprosy patients, their feelings in the first moment, the influence of their classmates' behavior, the preparation to perform the service, and the interest to continue working in this area. Results: It was possible to observe that students have knowledge about the disease, its causative agent, its mode of transmission, and its physical and social implications. We also noted that access to information was of utmost importance, so that most students did not create negative expectations regarding patient care. Conclusion: The study demonstrated how leprosy can still cause fear in the population and that this may influence the behavior of health professionals if they are not properly trained to deal with leprosy patients.
\end{abstract}

Keywords: Leprosy, Social Stigma, Occupational Therapy.

Autor para correspondência: Rogério Dubosselard Zimmermann, Departamento de Medicina Social, Av. Professor Moraes Rego, 1235, Cidade Universitária, CEP 50670-901, Recife, PE, Brasil, e-mail: rdzlegal@uol.com.br

Recebido em 16/10/2012; $1^{a}$ Revisão em 18/6/2013; $2^{a}$ Revisão em 27/6/2013; Aceito em 25/7/2013. 


\section{Introdução}

Hanseníase é uma doença infecciosa granulomatosa crônica, com período de incubação prolongado, causada pelo Mycobacterium leprae, parasita intracitoplasmático do macrófago, de alta infectividade e baixa patogenicidade, que afeta primariamente os nervos periféricos e a pele e é transmitida de pessoa a pessoa através do convívio de suscetíveis com doentes contagiantes sem tratamento (GOMES et al., 2005; SILVA; GOMES, 2007).

O Brasil é considerado o segundo país mais endêmico para hanseníase no mundo e o primeiro da América Latina, apresentando, em 2010, 1,56 casos para cada 10 mil habitantes. Informações recentes obtidas no banco de dados do Ministério da Saúde demonstram que, em 2012, o Brasil teve 38.611 casos notificados. A distribuiçáo de casos ocorre de forma desigual no território brasileiro, caracterizando-se por grande concentraçáo em áreas urbanas. O estado de Pernambuco ocupa o primeiro lugar do Nordeste, tendo apresentado na última década mais de 2.500 novos casos da doença a cada ano (BRASIL, 2012, 2013; HINRICHSEN et al., 2004; RANGEL; BARBOSA; MORALES, 2003).

A hanseníase é considerada uma doença de adulto pelo longo período de incubação, atingindo principalmente a faixa etária economicamente ativa. No entanto, as crianças também são suscetíveis a essa doença: no ano de 2010, apresentaram-se 2.461 casos em menores de 15 anos, um coeficiente de detecção desse grupo de 5,4 por 100 mil habitantes (BRASIL, 2012; IMBIRIBA et al., 2008).

O município de Recife foi considerado, segundo os critérios do Ministério da Saúde (portaria n. 125/SVS-MS, de 26/3/2009), uma área de hiperendemicidade, com um Coeficiente de Detecção médio de 60,7/1.000.000 habitantes no período 2001-2008. A cidade apresenta, em seu território, uma incidência da doença de forma heterogênea, estando acometidos 56 de seus 96 bairros (RECIFE, 2010).

Nos dias atuais, o medo e o preconceito ainda se fazem presentes na sociedade, produzindo nas pessoas com a doença reaçóes de raiva, negação, vergonha e culpa (MELLAGI; MONTEIRO, 2009).

A falta de informação sobre a doença, a incapacidade física e as deformidades causadas pelo comprometimento dos nervos periféricos são os motivos mais frequentes de discriminação e estigma. Esse último produz um relevante descrédito na vida do sujeito, permitindo que se estabeleça uma relação impessoal com o outro e tendo como representação as características típicas da classe do estigma, sendo as deformidades nomeadas, em algumas situaçóes, "defeitos" (DIAS; PEDRAZZANI, 2008; MELO, 2005).

Além disso, muitos doentes apresentam incapacidades na fase de diagnóstico ou as desenvolvem durante o tratamento, porém todos os doentes com perda ou diminuição da sensibilidade encontram-se em risco de desenvolver incapacidades adicionais. Tais incapacidades podem ser: paralisia facial do tipo periférico unilateral ou bilateral, paralisia do ramo orbicular do nervo zigomático, provocando o lagoftalmo, epífora e exposição da córnea; mão em garra; mão caída, pé caído, garra de artelhos, mal perfurante plantar (ARAUJO, 2003; DIAS; PEDRAZZANI, 2008).

Porém, além das incapacidades físicas, há perdas econômicas e traumas psicológicos, visto que a doença causa grande impacto no trabalho e na vida social do paciente. Muitos doentes apresentam dificuldades para desempenhar sua atividade laboral não só devido ao comprometimento físico, mas também pelo sofrimento emocional acarretado pela doença. O paciente de hanseníase também enfrenta dificuldades na estabilidade emocional, causadas por perdas sociofamiliares e do potencial de socialização (MARTINS, 2009; AQUINO et al., 2003).

Em face do quadro epidemiológico que se apresenta, da possibilidade de danos que podem afetar os portadores dessa doença e, especialmente, diante da discriminaçáo que podem sofrer, torna-se necessário o aprimoramento e o esforço contínuo de todos os profissionais envolvidos no tratamento, sendo essencial seu trabalho através de medidas que visem evitar a ocorrência de danos físicos, emocionais, espirituais e socioeconômicos. No caso de danos já existentes, a prevençáo deve ter como objetivo evitar as complicaçóes futuras (DIAS; PEDRAZZANI, 2008; DIAS; CYRINO; LASTÓRIA, 2007).

A Terapia Ocupacional se insere no cuidado a esses pacientes, entre outras atribuições, através de:

- Orientaçôes quanto aos autocuidados e técnicas de reeducação sensorial, com o objetivo de evitar agravos devido à redução ou falta de sensibilidade;

- Indicação, prescrição e orientação quanto ao uso de órteses para manutenção ou ganho de amplitude de movimento e realização de atividades para restauração da força muscular;

- Adaptaçôes dos utensílios utilizados no dia a dia e treino das atividades de vida diária, bem como adaptação das ferramentas de trabalho e orientação quanto ao desempenho laboral; 
- Orientaçáo e esclarecimentos ao paciente e aos familiares quanto à adesão ao tratamento e à prevençâo de incapacidades, além de realizar ações de reintegração do hanseniano à sociedade (ANDREAZZI; MOTA; VILLARINO, 2007).

Diante das significativas contribuiçóes que o terapeuta ocupacional pode oferecer no atendimento a essa clientela e diante do cenário que envolve a doença, este estudo teve como objetivo conhecer a percepção dos profissionais em formação acadêmica frente ao atendimento de pacientes acometidos de hanseníase.

\section{Procedimentos metodológicos}

Trata-se de uma pesquisa qualitativa de caráter descritivo exploratório, que utiliza como técnica entrevista aberta semiestruturada, com alunos regularmente matriculados no sétimo, oitavo e nono período, durante o segundo semestre de 2010 e que tinham cursado a disciplina Terapia Ocupacional em Hanseníase.

A disciplina possuía um caráter teórico-prático, nela se tratavam questôes referentes à doença, suas formas de tratamento e as abordagens utilizadas pelo terapeuta ocupacional, seguidas do primeiro contato com pacientes acometidos de hanseníase -durante a graduação - e da realização da intervenção terapêutica ocupacional, feita em um Posto de Saúde da Família ou na própria instituição de ensino.

As entrevistas foram realizadas por quatro pesquisadores após calibração, de forma que sua interferência fosse mínima, restringindo-se aos casos de necessidade, ou para evitar o término precoce da entrevista.

As entrevistas foram gravadas, após concordância e assinatura do TCLE (Termo de Consentimento Livre e Esclarecido) pelos respondentes, em seguida transcritas para análise de conteúdo, com posterior categorização temática (BARDIN, 2009). Inicialmente perguntou-se aos estudantes o que sabiam a respeito da hanseníase, pergunta essa elaborada com o intuito de ambientar o estudante com a entrevista. Foram utilizadas algumas questôes norteadoras como:

- Qual foi a sua expectativa antes de ter o primeiro contato com um paciente acometido de hanseníase?

- Você teve algum sentimento durante o atendimento do paciente com hanseníase?

- Se sim, quais foram os principais sentimentos?
- Você conversou com seu professor sobre esses sentimentos?

- Você comentou com outros colegas sobre esses sentimentos?

- Atualmente, como você se sente para lidar com o paciente acometido de hanseníase? Por quê?

- Você tem interesse em trabalhar na área de hansenologia? Por quê?

As respostas obtidas foram enquadradas em eixos principais e agrupadas de acordo com as percepçóes dos respondentes em relação aos medos, receios ou inseguranças, como também quanto ao nível de modificação ou ausência dessas posturas.

Para preservar a identidade dos respondentes, as entrevistas foram numeradas de 1 a 35 , por ordem de realização. Em seguida foram selecionadas as falas mais frequentes ou que tiveram destaque entre as entrevistas, sendo essas comparadas com a literatura existente sobre o tema.

O estudo foi pautado na resolução CNS n. 196/96 do Ministério da Saúde e teve início após a aprovaçáo pelo Comitê de Ética do Centro de Ciências da Saúde (CCS), sobre o registro n. 084/10.

\section{Resultados e discussão}

Participaram da pesquisa 35 alunos e os dados obtidos foram divididos, segundo a categorização temática, em seis eixos, de acordo com as respostas dos entrevistados

\subsection{O que é hanseníase?}

Quando os estudantes foram questionados a respeito do que sabiam sobre a hanseníase os aspectos mais citados foram acometimento dos nervos e deformidades físicas, bem como as incapacidades provocadas pela morbidade. Também foi citado que era uma doença infectocontagiosa, causada por um bacilo. As respostas estão coerentes com o encontrado na literatura.

Entrevistado 7: “[...] É uma doença que pode ser provocada por um bacilo, trazer alguns distúrbios neurológicos e comprometer a capacidade funcional do individuo, e as relaçóes pessoais, e envolve outras questôes também." Entrevistado 34: "Uma infecção causada pelo bacilo de Hansen que vai afetar tanto a parte motora quanto a sensorial e psicológica, posteriormente causando incapacidades [...] de componentes de Atividades de Vida Diária (AVD), lazer e o lado social da pessoa." 
É importante destacar que os entrevistados relatam a questão psicossocial que envolve a doença. Durante muitos anos, as ações promovidas pelo Estado para o controle da hanseníase foram segregadoras e excludentes devido à falta de conhecimento acerca das formas de tratamento ou mesmo da possibilidade de cura. O exílio sanitário era uma dessas ações: consistia em internar os pacientes em hospitaiscolônia afastados de todo o convívio social. Mesmo depois da descoberta do Mycobacterium leprae como causador da doença e da promulgação da lei que desobrigava a internaçáo compulsória, essa foi a realidade das pessoas acometidas pela hanseníase. Esse caráter de exclusão traz à doença marcas, além das físicas, uma vez que o paciente se vê vivendo em um lugar diferente, com pessoas diferentes, afastado de toda sua vida social.

\subsection{Expectativa do atendimento}

Quanto à expectativa em relação ao atendimento dos pacientes acometidos pela hanseníase, os estudantes demonstraram tranquilidade, sentindo-se preparados para o atendimento, especialmente por terem obtido informaçôes sobre a doença.

Entrevistado 8: "Pra mim foi normal, porque perto de onde eu morava tinha um hospital de leprosos, de hansênico [...]. Então quando eu era pequeno, sempre escutei muitas histórias sobre isso e muitas brincadeiras [...] e outras pessoas me explicavam que não era isso, que não se pegava desse jeito [...]" Entrevistado 25: "Não tive problema nenhum porque nas primeiras aulas, antes de entrar em contato com o paciente, se explica, nâo tive nenhum receio." Entrevistado 13: "[...] como tive as aulas teóricas antes, esclareceu muitas coisas e eu consegui participar das aulas práticas sem nenhum preconceito."

Eidt (2000) relata que, ante o surgimento constante de novos casos, as campanhas de esclarecimento e prevençáo das doenças realizadas pelas autoridades sanitárias parecem ser insuficientes, levando à desinformação dos profissionais de saúde, assim como ao desconhecimento da população.

Para Dias, Cyrino e Lastória (2007), é importante fornecer aos estudantes conhecimento sobre o tema para que desenvolvam atitudes e habilidades que permitam o cuidado adequado ao paciente. $\mathrm{O}$ autor entende também como necessário abordar questôes relativas ao preconceito e de como trabalhá-lo no meio estudantil. Portanto, tendo esse conhecimento, o futuro profissional poderia atuar na orientação sobre a hanseníase, seja aos doentes ou à população em geral.

No presente estudo observou-se o desconhecimento de alguns estudantes acerca do tema antes de cursarem a disciplina, o que demonstra ainda uma falha na disponibilidade de informaçóes sobre a doença na mídia em geral.

Entrevistado 18: "Era complicado, eu não tinha informação nenhuma, nunca tinha buscado nada, não era preconceito, mas acho que era ignorância de náo saber como é que se pegava, [...] acho que medo de encontrar alguém contaminado e se contaminar." Entrevistado 35: "Sinceramente, no começo eu era meio assim em relação à hanseniase por que não sabia qual era a forma de contágio, então eu tinha medo, mas depois que paguei a cadeira [cursou a disciplina] vi que não era esse bicho todo."

Foi possível identificar através dos relatos o preconceito que persiste na sociedade e que esse fato pode ser modificado através da informação sobre a doença. Essa questão foi identificada em outros estudos, como o de Borenstein et al. (2008), que afirmaram originar-se essa situação basicamente em função da falta de informação por parte da população. Dias, Cyrino e Lastória (2007) dizem que o preconceito está relacionado ao medo de se adquirir a doença e à falta de informaçáo.

\subsection{Primeiro contato com o paciente}

Quando questionado sobre o primeiro contato com o paciente com hanseníase e como se sentiram nesse momento, as respostas, em sua maioria, não registraram problema com o atendimento ou intimidação com o procedimento.

Entrevistado 34: "[...] eu tava tranquila por conta da aula que a gente teve antes, muito esclarecedora." Entrevistado 28: "eu não sabia o que era hanseniase, eu fiquei curiosa e ao mesmo tempo apreensiva, [...] mas quando você começa a estudar fica muito tranquilo."

Outros relataram sentir nervosismo, não por estar atendendo uma pessoa com hanseníase, mas por se tratar de um ciclo acadêmico no qual há o primeiro contato com pacientes.

Entrevistado 33: "Pela doença eu não tinha medo, era mais a ansiedade de ter contato com o paciente e saber a realidade dele." Entrevistado 29: "Fiquei muito nervosa porque eu nunca tinha tido contato com pacientes [em geral]." 
Martins e Caponi (2010) relatam que as sequelas são responsáveis pelo estigma sofrido pelo indivíduo, provocando limitaçóes em sua vida, em diversas dimensóes, e isso foi constatado no presente estudo, admitindo-se que o aspecto físico do hansênico seja um fator que provoca intimidação em alguns estudantes.

Entrevistado 13: "Nervosa, não por ser hanseniase, mas apenas por ser um paciente que estava em aula e eu tinha que atender, mas não por ser hanseniase de forma alguma [...]. E também o primeiro paciente que eu vi não tinha nenhum aspecto visual forte, era uma pessoa que você olhava e nem dizia que tinha hanseníase [...]" Entrevistado 20: "Não tinha nada de impacto visual não. Nunca peguei nenhum paciente com nenhuma contratura, nem úlcera." Entrevistado 27: "[...] eu não vi nenhuma questão mais diferente [...] coisa que chocasse [...]"

Para Dias, Cyrino e Lastória (2007), o preconceito revela-se na aparência do doente, sobretudo em relação às suas manchas e incapacidade física. Já para Borenstein et al. (2008), as instituiçôes, ou leprosários, são responsáveis por um tratamento excludente dos pacientes com hanseníase, tendo como consequência a imagem de "horror à doença" e o estigma social. Esse estigma pode ser constatado na fala do entrevistado 12 :

Entrevistado 12: "Fiquei intimidada, eu queria luva, mas a professora não me deixou colocar luvas. Por que cria uma barreira fisica entre você e os pacientes e minha intenção era exatamente essa." Entrevistado 31 "[...] Eu imaginava ver coisas muito mais graves, não as coisas básicas que a gente vê hoje em dia."

Esse pensamento era comum nos hospitais colônia para leprosos na década de 1940, como relatado por Borenstein et al. (2008) em seu estudo sobre o Hospital Colônia Santa Tereza de São Pedro de Alcântara, Santa Catarina. Nessa instituição, os pacientes eram segregados em duas áreas, uma destinada às residências dos funcionários e outra para os doentes, as áreas eram separadas por muros. O estigma era tanto que a instituição possuía uma moeda própria, com o intuito de restringir o contato com o mundo externo, pois se tinha a ideia de que os hansênicos poderiam espalhar a doença através do manuseio do dinheiro normal.

Comparando as respostas sobre a expectativa do atendimento e sobre o primeiro contato com o paciente percebeu-se que, em geral, os sentimentos mantiveram-se iguais.

\subsection{Comportamento da turma durante a disciplina de hanseníase}

Martins (1997), Pereira (2002) e Pino (1993), ao estudarem a teoria vygotskyana, relatam que para o indivíduo formar seus conceitos ele precisa da influência de fatores inatos, empíricos, bem como a influência do meio social em que está inserido. Dentre esses, o meio possui maior influência na formação dos conceitos do indivíduo. Contudo, essa influência náo ocorre de maneira determinista, pois se pode constatar na fala do entrevistado 8 que fatores empíricos tiveram mais influência do que o meio social, aqui representado pelo meio acadêmico.

Entrevistado 8: "Dos colegas da disciplina não. Acho que todos já estavam sabendo como é que se pegava, como se transmite, tudo isso [...] os comentários vinham do lado de fora, às vezes de outros profissionais de saúde e de outros colegas, principalmente de periodo mais baixos [...]"

Outros entrevistados narraram que durante os atendimentos não houve repercussóes que influenciassem no comportamento da turma de forma negativa e que esse fato está ligado às informaçoes passadas pela disciplina. Como demonstra o trecho a seguir:

Entrevistado 5: "No começo, todo mudo ficava assustado, por que é uma doença que assusta um pouco, mas já escutei fora muito mais, de pessoas que não tinham conhecimento. [...] dos estudantes que estudaram comigo, parentes e pacientes não muito, estava todo mundo bem orientado."

Pesquisa realizada na Universidade Federal de São Carlos registrou que desde 1988 os universitários, funcionários da instituição e portadores de hanseníase percebem a diminuição do preconceito em relação à doença, fato esse creditado às campanhas educativas e aos avanços da medicina (TOYODA, 1991).

\subsection{Preparo para atender}

Alguns autores relatam que a grande maioria dos profissionais da área de saúde necessita de informação e de conhecimento sobre a hanseníase (DIAS; CYRINO; LASTÓRIA, 2007).

A maioria dos estudantes pesquisados se considerou preparada para atender pacientes acometidos pela hanseníase devido a uma boa abordagem feita pela disciplina.

Entrevistado 19: "[...] acho que eu me vejo talvez mais tranquila, por que ai eu já sei como me direcionar, como saber o que fazer 
pelo menos a principio com cada pessoa, me portar melhor com cada paciente em especifico com paciente com hanseniase." Entrevistado 25: "não tive problema nenhum não por que nas primeiras aulas, antes de entrar em contato com o paciente, se explica, não tive nenhum receio." Entrevistado 16: "Me sinto mais segura, ainda mais quando a gente já sabe as informaçóes [...] Me sinto mais segura pra ajudar, a cadeira [disciplina] ajudou muito."

Contudo, o aluno pode até ter aprendido a teoria, todavia se ela não for trabalhada da forma adequada, poderá persistir com medo (DIAS; CYRINO; LASTÓRIA, 2007). Nesse caso, fica evidente a importância de se abordar temas polêmicos na prática de ensino, principalmente devido ao estigma social, que em relação à hanseníase, existe até hoje. Feliciano e Kovacs (1997) considera que o medo do contágio pressupóe o medo de suas consequências físicas e sociais ainda tão associadas à visão estigmatizante da doença.

\subsection{Atuação na área de hanseníase}

A maioria dos estudantes relatou que trabalharia na área de hanseníase. Entretanto, foi citada a necessidade de se obterem mais informaçóes sobre $\mathrm{o}$ aspecto psicossocial.

Entrevistado 34 "[...] Eu pude ver muito claramente a influência do contexto histórico. Acho que não tinha noçâo do quanto a hanseniase pode marcar uma pessoa no físico, sensorial e emocional." Entrevistado 3: "Eu tenho que estudar muito antes. Trabalharia, ficaria disposta para atender além da avaliação [Avaliação Simplificada das Funções Neurais e Complicaçóes], [...] me prenderia mais nos componentes psicossociais [...] a gente sabe que tem preconceito [...]"

É necessário ratificar a importância de se trabalhar o sofrimento psicológico desses pacientes e que os profissionais de saúde deverão saber lidar com as situaçôes que requerem essa abordagem. Alguns estudantes, mesmo após terem recebido as informaçôes sobre a doença, podem persistir com medo (DIAS; CYRINO; LASTÓRIA, 2007).

Diante disso, o estudante pode descartar a hipótese de atuação nessa área, como na fala do entrevistado 23.

Entrevistado 23: "Não, pelo fato que vai chegar paciente de todos os tipos, tomando medicamento, sem tá tomando, e eu náo vou me sentir à vontade. Apesar que eu sei que não transmite de uma hora para outra, precisa daquele convivio, mas mesmo assim prefiro evitar, não me acho preparada."
Mesmo assim, as informaçôes adquiridas durante a graduação proporcionaram o interesse de vários estudantes em atuar na área de Hansenologia, por se tratar de um campo rico para atuação do terapeuta ocupacional.

Entrevistado 34 "[...] Percebi claramente o papel da TO, que até então eu não tinha percebido." Entrevistado 24: "Eu gostaria, por que eu vi que é um campo bem aberto para a Terapia Ocupacional [...]"

O terapeuta ocupacional compóe o quadro de profissionais habilitados a trabalhar no tratamento e reabilitaçáo de pacientes com hanseníase e sua atuação está presente na prevenção e na reabilitação funcional e psicossocial, acompanhando não só o paciente, mas a sua família, entendendo e intervindo em seu contexto familiar e social.

A manutenção ou melhora do estado físico, socioeconômico e emocional do paciente é o principal objetivo das ações de prevenção de incapacidades em hanseníase, levando-se em conta a sua realidade e considerando as suas capacidades e necessidades.

$\mathrm{Na}$ intervenção terapêutica ocupacional pode-se também realizar palestras informativas nos centros de saúde e em outros locais, chamando a atenção da população para os possíveis sinais e sintomas, tratamento, prevenção e, principalmente, conscientizando-a de que a hanseníase tem cura, buscando eliminar o estigma que ainda envolve a doença.

\section{Considerações finais}

Pôde-se observar que os alunos possuem conhecimento sobre a doença, o agente causador, a forma de transmissão, suas implicações físicas e sociais e que o acesso à informação foi de importância significativa para que a maioria dos alunos não criasse expectativas negativas em relação ao atendimento desses pacientes, tornando o primeiro contato uma experiência tranquila e, de uma forma geral, distante de preconceitos.

As informaçôes prestadas aos alunos foram fundamentais para torná-los confiantes quanto aos procedimentos a serem realizados e para impedir que houvesse manifestaçóes capazes de contaminar o grupo em relação à existência de possível preconceito, além de despertar nos alunos o desejo de trabalhar na área de Hansenologia. $\mathrm{O}$ estudo possibilitou também demonstrar como a hanseníase ainda provoca medo na população e que esse fato pode influenciar o comportamento do profissional de saúde caso ele não tenha capacitação para lidar com o paciente. 
A iniciativa do curso de Terapia Ocupacional de incluir na grade curricular uma disciplina que procura esclarecer sobre a doença e os procedimentos a serem realizados diante das suas manifestaçóes, trazendo para a discussão as influências sociais acerca do tema, favorecem o crescimento do profissional em formação para o cuidado biopsicossocial da pessoa acometida pela hanseníase. Devemos ressaltar a importância de serem abordadas outras doenças infectocontagiosas de caráter estigmatizante, com o propósito de estimular a discussão acerca desse tema e assim diminuir o preconceito.

\section{Referências}

AQUINO, D. M. C. et al. Avaliação do programa de controle da hanseníase em um município hiperendêmico do Estado de Maranhão, Brasil. Revista da Sociedade Brasileira de Medicina Tropical, Uberaba, v. 36, n. 1, p. 57-64, 2003.

ANDREAZZI, A. L. J.; MOTA, G. A.; VILLARINO, T. P. Hanseníase: avaliação da sensibilidade com os monofilamentos de semmes Weinstein. Vila Alta: UNISALESIANO, 2007. Disponível em: <http://www. unisalesiano.edu.br/encontro2007/trabalho/aceitos/ CC33717473875.pdf>. Acesso em: 27 set. 2009.

ARAUjO, M. G. Hanseníase no Brasil. Revista da Sociedade Brasileira de Medicina Tropical, Uberaba, v. 36, n. 3, p. 373-382, 2003. Disponível em: <http:// www.scielo.br/scielo.php?script=sci_arttext\&pid=S0037$86822003000300010 \& \operatorname{lng}=e n \& n r m=i s o>$. Acesso em: 26 nov. 2009.

BARDIN, L. Análise de conteúdo. Lisboa: Ediçōes 70, 2009. BORENSTEIN, M. S. et al. Hanseníase: estigma e preconceito vivenciados por pacientes institucionalizados em Santa Catarina (1940-1960). Revista Brasileira de Enfermagem, Brasília, v. 61, p. 708-712, 2008. Número especial. Disponível em: <http://www. scielo.br/scielo.php?script=sci_arttext\&pid=S0034$71672008000700009 \& \operatorname{lng}=$ en\&nrm=iso>. Acesso em: 6 fev. 2011.

BRASIL. Ministério da Saúde. Secretaria de Vigilância em Saúde. Departamento de Vigilância em Doenças Transmissíveis. Plano integrado de açöes estratégicas de eliminação da hanseníase, filariose, esquistossomose e oncocercose como problema de saúde pública, tracoma como causa de cegueira e controle das geohelmintiases: plano de ação 2011-2015. Brasília, 2012. Disponível em: <http://bvsms.saude.gov.br/bvs/publicacoes/ plano_integrado_acoes_estrategicas_2011_2015.pdf>. Acesso em: 1 jun. 2013.

BRASIL. Ministério da Saúde. Departamento de Informática do SUS - DATASUS. Hanseníase: casos confirmados notificados no Sistema de Informação de Agravos de Notificação: Sinan Net. Brasília, 2013. Disponível em: <http://dtr2004.saude.gov.br/sinanweb/ tabnet/tabnet?sinannet/hanseniase/bases/Hansbrnet. def>. Acesso em: 1 jun 2013.
DIAS, A.; CYRINO, E. G.; LASTÓRIA, J. C. Conhecimentos e necessidades de aprendizagem de estudantes de fisioterapia sobre a hanseníase. Hansenologia Internationalis, Bauru, v. 32, n. 1, p. 9-18, 2007. Disponível em: <http://periodicos.ses.sp.bvs.br/scielo.php?script=sci arttext\&pid $=$ S1982-51612007000100002\&lng=pt $>$. Acesso em: 6 fev. 2011.

DIAS, R. C.; PEDRAZZANI, E. S. Políticas públicas na Hanseníase: contribuição na redução da exclusão social. Revista Brasileira de Enfermagem, Brasília, v. 61, p. 753-756, 2008. Número especial. Disponível em: <http:// www.scielo.br/scielo.php?script=sci_arttext\&pid=S0034$71672008000700016 \& \operatorname{lng}=$ en\&nrm=iso $>$. Acesso em: 17 set. 2009.

EIDT, L. M. O mundo da vida do ser hanseniano: sentimentos e vivências. 2000. 252 f. Dissertação (Mestrado em Educação)-Pontifícia Universidade Católica Do Rio Grande Do Sul, Porto Alegre, 2000.

FELICIANO, K. V. O.; KOVACS, M. H. Opinióes sobre a doença entre membros da rede social de pacientes de hanseníase no Recife. Revista Panamericana de Salud Pública, Washington, v. 1, n. 2, p. 112-118, 1997. Disponível em: < http://www.scielosp.org/scielo. php?script=sci_arttext\&pid=S1020-49891997000200004>. Acesso em: 10 fev. 2011. http://dx.doi.org/10.1590/ S1020-49891997000200004

GOMES, C. C. D. et al. Perfil clínico-epidemiológico dos pacientes diagnosticados com hanseníase em um centro de referência na região nordeste do Brasil. Anais Brasileiros de Dermatologia, Rio de Janeiro, v. 80, p. 283-288, 2005. Suplemento 3. Disponível em: <http:// www.scielo.br/scielo.php?script=sci_arttext\&pid=S036505962005001000004\&lng=en\&nrm=iso >. Acesso em: 17 set. 2009.

HINRICHSEN, S. L. et al. Aspectos epidemiológicos da hanseníase na cidade de Recife, PE em 2002. Anais Brasileiros de Dermatologia, Rio de Janeiro, v. 79, n. 4, p. 413-421, 2004. Disponível em: <http://www. scielo.br/scielo.php?script=sci_arttext\&pid=S0365$05962004000400003 \& \operatorname{lng}=$ en $\& n r m=$ iso $>$. Acesso em: 17 set. 2009.

IMBIRIBA, E. B. et al. Perfil epidemiológico da hanseníase em menores de quinze anos de idade, Manaus (AM), 19982005. Revista de Saúde Pública, São Paulo, v. 42, n. 6, p. 1021-1026, 2008. Disponível em: <http://www.scielo.br/ scielo.php?pid=S0034-89102008000600007\&script=sci arttext>. Acesso em: 03 jun. 2013. http://dx.doi. org/10.1590/S0034-89102008005000056

MARTINS, M. A. Qualidade de vida em portadores de Hanseniase. 2009. 98 f. Dissertação (Mestrado em Psicologia)-Universidade Católica Dom Bosco, Campo Grande, 2009.

MARTINS, J. C. Vygotsky e o papel das interaçōes sociais na sala de aula: reconhecer e desvendar o mundo. São Paulo: FDE, 1997. Disponível em: <http://www.crmariocovas. sp.gov.br/pdf/ideias_28_p111-122_c.pdf>. Acesso em: 10 fev. 2011. 
MARTINS, P. V.; CAPONI, S. Hanseníase, exclusão e preconceito: histórias de vida de mulheres em Santa Catarina. Ciência \& Saúde Coletiva, Rio de Janeiro, v. 15, p. 1047-1054, 2010. Suplemento 1. Disponível em: <http://www.scielosp.org/scielo.php?script=sci_ arttext\&pid=S1413-81232010000700011\&lng=en. doi: 10.1590/S1413-81232010000700011>. Acesso em: 06 fev. 2011.

MELLAGI, A. G.; MONTEIRO, Y. N. O imaginário religioso de pacientes de hanseníase: um estudo comparativo entre ex-internos dos asilos de Sáo Paulo e atuais portadores de hanseníase. História, Ciências, SaúdeManguinhos, Rio de Janeiro, v. 16, n. 2, p. 489-504, 2009. Disponível em: <http://www.scielo.br/scielo.php?script=sci_ arttext\&pid=S0104-59702009000200011\&lng=en\&nrm =iso $>$. Acesso em: 17 set. 2009. http://dx.doi.org/10.1590/ S0104-59702009000200011

MELO, Z. M. Os estigmas: a deterioração da identidade social. Minas Gerais: PUC Minas, 2005. Disponível em: <http://proex.pucminas.br/sociedadeinclusiva/anaispdf/ estigmas.pdf $>$. Acesso em: 10 jun. 2013.

PEREIRA, M. Desenvolvimento psicológico segundo Vygotsky: papel da educação. Revista do ISED e ISEC,
Divinópolis, n. 3, 2002. Disponível em: <http://www2. funedi.edu.br/revista/revista-eletronica3/artigo9-3.htm>. Acesso em: 10 fev. 2011.

PINO, A. L. B. Processos de significação e constituição do sujeito. Temas em Psicologia, Ribeirão Preto, v. 1, n. 1, p. 17-24, 1993. Disponível em <http://pepsic.bvsalud.org/ scielo.php?script=sci_arttext $\&$ pid=\$1413-389X1993000 100004\&lng=pt\&nrm=iso $>$. Acesso em: 10 fev. 2011.

RANGEL, C. P.; BARBOSA, M. A. S.; MORALES, P. W. Equipe de Saúde da Familia x Programa para o Controle de Hanseniase. Recife, 2003.

RECIFE. Secretaria Municipal de Saúde. Plano Municipal de Saúde 2010/2013. Recife, 2010. Disponível em: <http:// www.recife.pe.gov.br/noticias/arquivos/5916.pdf >. Acesso em: 20 mar. 2012.

SILVA, A. J. C.; GOMES, J. K. S. Abandono do tratamento da hanseniase em uma unidade de saúde do Recife. Recife, 2007.

TOYODA, C. Y. Preconceito: a visão dos hansenianos e da população universitária com relação à hanseníase. Cadernos de Terapia Ocupacional, São Carlos, v. 2, n. 2, p. 123-144, 1991.

\section{Contribuição dos Autores}

Rogério Dubosselard Zimmermann: Concepção do texto, responsável pela pesquisa e orientador. Sémares Genuino Vieira: Redação do texto, pesquisa bibliográfica e colaboradora na coleta e análises dos dados. Nara Carollina Mattos Sandes: Redação do texto, pesquisa bibliográfica e colaboradora na coleta e análises dos dados. Thaisa Damasceno de Albuquerque Angelo: Redação do texto, pesquisa bibliográfica e colaboradora na coleta e análises dos dados. Viviane Cássia Aranda de Souza: Redação do texto, pesquisa bibliográfica e colaboradora na coleta e análises dos dados.

\section{Notas}

${ }^{1}$ Pesquisa realizada após aprovação pelo Comitê de Ética do Centro de Ciências da Saúde (CCS) da Universidade Federal de Pernambuco (UFPE), sobre o registro n. 084/10. 